\title{
Power, Control, Communities and Health Inequalities. Part II: Measuring Shifts in Power
}

\author{
Authors: \\ Corresponding Author: Dr Ruth Ponsford; London School of Hygiene and Tropical Medicine, \\ Health Services Research\& Policy, London ruth.ponsford@1shtm.ac.uk \\ Dr Michelle Collins; Lancaster University, Division of Health Research, Lancaster, UK \\ michelle.collin@lancaster.ac.uk
}

Dr Matt Egan; London School of Hygiene and Tropical Medicine, Health Services Research\& Policy, Londonmatt.egan@1shtm.ac.uk

Dr Emma Halliday Lancaster University, Division of Health Research, Lancaster, UK e.halliday@lancaster.ac.uk

Dr Sue Lewis University of Durham UK sue.lewis@durham.ac.uk

Dr Lois Orton Department of Public Health and Policy, University of Liverpool, Liverpool, UK L.C.Orton@Liverpool.ac.uk

Dr Kate Powell University of Sheffield, Public Health Section k.powell@sheffield.ac.uk

Dr Amy Barnes, University of Sheffield, Public Health Section a.barnes@sheffield.ac.uk

Professor Sarah Salway, University of Sheffield, Department of Sociological Studies Sheffield UK s.salway@sheffield.ac.uk

Dr Anne Townsend Lancaster University, Division of Health Research, Lancaster, UK a.townsend5@lancaster.ac.uk

Professor Margaret Whitehead University of Liverpool, Department of Public Health and Policy, Liverpool UK $\underline{\text { mmw@Liverpool.ac.uk }}$

Professor Jennie Popay; Senior Author, Lancaster University, Division of Health Research, Lancaster, UK j.popay@lancaster.ac.uk

Funding: This research was supported by the NIHR School for Public Health Research (SPHR) [grant number SPHR-SWP-IEQ-PH1] . The views expressed are those of the authors and not necessarily those of the NHS, the NIHR or the Department of Health and Social Care. The study was carried out independently from Local Trust and does not receive funding from Local Trust or the Big Lottery Fund.

Ethics: Ethical approval for the study was granted by the University of Lancaster Research Ethics Committee on $03^{\text {rd }}$ February 2014.

Acknowledgements: We wish to acknowledge the input of the wider members of the research team, a partnership of researchers based at Universities of Liverpool and Lancaster (LiLaC Collaboration), Universities of Exeter and Sheffield, the London School for Hygiene and Tropical Medicine and Fuse (the Centre for Translational Research in Public Health, a collaboration between Newcastle, Durham, Northumbria, Sunderland and Teesside Universities.) The team thanks Local Trust and Big Local partnerships and residents for their support and contrbutions to the research. 


\section{SUMMARY}

In the health field there is great interest in the role empowerment might play in reducing social inequalities in health. Empowerment is understood here as the processes of developing capabilities that individuals and/or communities need to exercise control over decisions and actions impacting on their lives and health. There is a fundamental problem, however, in identifying and measuring capabilities for collective control control that emerge at the level of the collective, with much of the existing literature focussing on individual measures even where community level processes are concerned. Collective measures need to capture the dynamics of interactions within and between groups, not simply aggregate individual level measures. This paper, Part 2 in a three-part series, takes up the challenge of identifying qualitative markers of capabilities for collective control. We applied the Emancipatory Power Framework (EPF) reported in Part 1 of the series, to qualitative data generated during a longitudinal evaluation of a major English area-based empowerment initiative, the Big Local (BL). We identified empirical 'markers' of shifts towards greater collective control pertaining to each of the 'power' dimensions in the EPF -'power within', 'power with' and 'power to' - and markers of communities exercising 'power over' other institutions/community members. These markers can usefully be applied in the evaluation planning and evaluation of empowerment initiatives. Part 3 in the series uses these markers and a second analytical framework developed during our evaluation of BL to explore how power dynamics unfold in participatory spaces in $\mathrm{BL}$ neighbourhoods. [words $=245$ ]

Keywords: Area based initiatives; Evaluation; Health inequalities; Community empowerment; Collective control; Social determinants of health

\section{Word counts:}

Abstract: 245.

Main text: 5131.

Box: 390 .

References: 643. 


\section{INTRODUCTION}

Community empowerment as a route to political and social transformation for greater equity is enshrined in foundational health promotion/public health statements (WHO 1997; WHO, 1986). Definitions vary but here we define community empowerment as the processes through which communities of interest or place develop the capabilities needed to exercise collective control over decisions and actions impacting on their lives and health. In recent decades, the priority afforded to local empowerment initiatives in health promotion/public health work has been supported by a growing body of evidence demonstrating that 'control over one's destiny' (Syme, 1989) is a fundamental determinant of health and that lack of control could be a significant cause of health inequalities. Community empowerment is thus now integral to the Global Sustainable Development Goals and many local, national and international strategies for social and health development (e.g. WHO EURO 2013, 2019; UN Economic and Social Council, 2019; United Nations 2019). There are important conceptual differences, however, between empowerment operating at the individual and collective levels and the resulting impacts/outcomes, which in turn lead to differing measurement challenges. In this paper, Part 2 of three, we aim to address some of these measurement challenges.

\section{INDIVIDUAL-LEVEL EMPOWERMENT}

Individual-level empowerment usually refers to the process whereby individuals gain a greater sense of self- efficacy, autonomy and perceived control over decisions and actions in their daily lives (Zimmermann, 2000). There is evidence of a strong association between greater perceived control and better health outcomes at this individual level (Whitehead et al., 2014). There is also evidence from longitudinal studies of a pathway from lower perceived control to poorer health outcomes for people in lower socio-economic positions, which explains statistically some of the observed socio-economic inequalities in health (Orton et al., 2019). In response to this evidence, interventions, particularly in the work environment, have been developed to promote individual psycho-social empowerment and instruments produced to measure this construct. Most of these arise from quantitative surveys and involve: (i) self-reported measures of attitudes and beliefs about the degree of control a person has over day-to-day decisions, perceptions of personal competence and effectiveness (Cyril et al., 2016); and (ii) indices of cognitive, emotional and behavioural domains at the individual level (Speer and Peterson, 2000). Individual-level measurement is, however, inadequate to deal with the the collective impacts/outcomes emerging from community level processes which are of major interest to health promotion and frameworks for measuring these remain limited. 


\section{COLLECTIVE CONTROL AND COMMUNITY EMPOWERMENT}

In Part 1 of this series (Popay et al., 2020), we argued that the construct of collective control understood as the outcome of empowerment processes has greater analytical and practical advantage for health policy and practice, than the commonly used concept of "community empowerment". Most obviously, the term 'collective' avoids the ambiguous and contested concept of "community" (Reynolds et al., 2015), emphasising joint, collaborative action by people with shared interests, who may or may not be connected by place. Second, and more significantly, we argued that the concept of 'collective control' can help practitioners move beyond the 'inward gaze' dominating many contemporary community initiatives, which

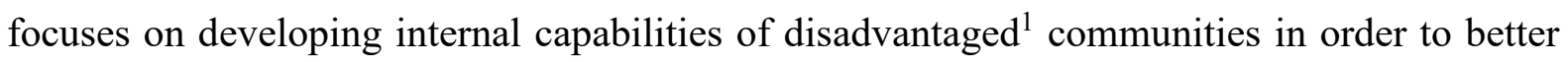
enable them to 'cope' with their proximal living circumstances. This inward gaze is embedded, for example, in concepts such as community competencies, capacities, assets, resilience and social capital. Clearly, it is important that people experiencing the brunt of inequalities (however defined) are supported to develop their internal capabilities. It is also imperative, however, that this inward gaze in local community initiatives is complemented by an equally strong outward gaze aimed at supporting communities to mobilise these capabilities to collectively take more control over the external structures and conditions that drive social, economic and health inequalities. Thirdly ( and linked to this) is the widely shared view that the notion of community empowerment has 'lost it's power' and has often been tokenistic with little control actually transferred to community members in practice (Popay et al., 2020). The construct of collective control, however, places power and the outward gaze at its core.

\section{ANALYTIC FRAMEWORK: POWER AS CAPABILITEIS FOR COLLECTIVE CONTROL}

In Part 1 of this three-part series, we set out a detailed framework that conceptualises the capabilities communities require to exercise collective control over decisions and actions impacting on their lives and health as different forms of power (Popay et al., 2020). This Emancipatory Power Framework (EPF), summarised in Box 1, draws heavily on the concepts of 'Power Within', 'Power With' and 'Power To' , which have their roots in feminist theory (Rowlands, 1997; Arendt, 1970; Starhawk, 1987; Allen, 1998, 2011).

\footnotetext{
${ }^{1}$ We use 'disadvantaged' throughout the paper to encompass the multi-dimensional nature of the adverse social and economic circumstances experienced by less privileged communities and neighbourhoods.
} 
In the EPF, the three concepts of power have been adapted from the individual level to the collective. Here, 'Power Within' refers to collective capabilities internal to a community and awareness of these. 'Power With', originally defined by Arendt (1970:44) as "the power that resides in collective action or solidarity", refers to the power that emerges when a community acts with other agencies and/or communities in the pursuit of shared ends. 'Power To' refers to the exercise of collective control capabilities to achieve desired ends and includes both the establishment of organisational structures and procedures for collective decisions and actions and the outcome of these.

The three dimensions in the EPF reflect an understanding of power as generative, expansive and non-dominating: emanating from relationships with others (Rowlands, 1997). As Pearce (2013) notes, these forms of collective non-dominating power, emergent within and between residents at a neighbourhood level, should be recognised as enhancing the debate about what constitutes effective and transformative change towards equity. These emancipatory forms of power increase the ability of residents to change their neighbourhoods, and wider social systems, to improve social and health outcomes and may also be health enhancing in themselves.

Recognising the potential for some groups in communities to exert illegitimate 'power over' others is also important. As Rissel (1994) has argued, the 'zero sum' concept of power, where one's loss is another's gain, can't be ignored when action is aimed at political change and (re)distribution of opportunities and resources. A fourth dimension - Power Over - is therefore included in the EP Framework, recognising that in some circumstances power does operate as a finite resource: when for example, a community seeks to exert Power Over an external agency in the pursuit of change or when one group exercises Power Over another within the same neighbourhood. Changes in one power dimension in the EPF will feed back and amplify or dampen other dimensions. Relationships are not necessarily linear but the development and exercise of Power To and Power With, for example, initially at least, requires some degree of Power Within.

\section{COLLECTIVE CONTROL: THE MEASUREMENT PROBLEM}

If the construct of collective control capabilities, understood here as different forms of power, is to be of benefit to health policy and practice, then we have to find ways to identify and 
measure these capabilities at the level of the collective. Collective impacts/outcomes, however, by their very nature, cannot be captured adequately by simply aggregating measures of psychological empowerment of individuals in a community or group (Wallerstein 2006; Lawson and Kearns, 2014). We need measures that capture the dynamics of interactions within and between the collective, on the principle that the whole is greater than the sum of its parts.

As noted above, the overwhelming majority of instruments used to measure the outcomes from empowerment processes relate to individual empowerment and are quantitative. A recent systematic review of empowerment measures (Cyril et. al. 2016), for instance, reported that only two studies measured collective empowerment and a further one organisational empowerment. Attempts have been made to develop more nuanced scales, in particular building on Laverack's work on 'domains' (2005; 2006), and the use of 'spidergrams' to assess multiple dimensions of community participation by Draper and colleagues (2010). Not-withstanding these innovations, however, in their 2016 review Cyril and colleagues highlighted the shortcomings in understanding that arises from the use of quantitative scales alone. More recently, in their synthesis of evidence on existing approaches to measuring community empowerment, Laverack and Pratley confirmed that "standard quantitative indicators are insufficient to measure the complexity of the concept" (2018:vii) and advocate combining these with some form of rapid qualitative assessment. Orton and Ponsford et al. (2019) make a similar argument, highlighting the value of indepth qualitative work for capturing the complexity of such community level processes.

The research reported here was part of an on-going longitudinal evaluation of a large-scale community empowerment programme called Big Local $(B L)$ being implemented in 150 neighbourhoods across England. We aimed to develop empirical markers of changes in the different forms of power - capabilities for collective control - identified in our Emancipatory Power Framework power - as they occurred in BL neighbourhoods in the first three years of implementation. In undertaking this work we have sought to contribute to scientific debates about how best to measure different forms of power intrinsic to the development of the collective control that community initiatives in the health field should aim to develop. In doing so we have taken up the challenge of identifying accessible qualitative 'measures' that capture this complexity. Secondly, we aimed to develop practical qualitative markers that we could apply in our long-term evaluation of the BL and that could be of use to others involved in designing, delivering and/or evaluating community empowerment initiatives. 


\section{METHODS}

\section{The study setting: the Big Local Placed Based Initiative}

BL is funded by the English Big Lottery Charity and managed by a not-for-profit organisation: Local Trust. This ten+-year initiative involves residents of 150 relatively disadvantaged areas in England receiving $£ 1$ million per area to use to improve their neighbourhoods. BL communities did not apply for this funding. Intially the funder produced a long-list of English neighbourhoods that had not received significant national lottery funding previously. The final $150 \mathrm{BL}$ areas were selected from this list, following discussions between the funder and key stakeholders from local government and the local voluntary and community sector.

Residents in each neighbourhood decide collectively how to use funds, within a common overall framework comprising: forming a resident-led governance Partnership; involving the wider community in developing and delivering a local plan; reviewing progress overtime; and adapting the plan as necessary. BL Partnerships are encouraged, but not required, to collaborate with other organisations. The programme is innovative in having the central objective of giving power over the $£ 1$ million to the residents of BL areas, unlike most previous place-based interventions that put ultimate financial control in the hands of local government or other professional institutions. Governance over how the money is spent in each area rests with a resident-led Partnership but, as we describe in the third paper in this series (Powell et al., 2020), many Partnerships open up the "governance space" to the wider "community of place' to enable them to contribute to priority setting, decision making and plan delivery.

\section{The evaluation design}

The markers of changes in each power dimension in the Emancipatory Power Framework were identified in an analysis of qualitative data collected during the first phase of our longitudinal evaluation of BL. More details of this study are available at: https://communitiesincontrol.uk/. This phase aimed to develop a 'thick' description of the first 3 years of implementation. We therefore adopted an interpretative approach, utilizing qualitative methods to understand how the programme unfolded through the subjective viewpoints of the residents and other stakeholders involved within their local context. Two waves of fieldwork were conducted between March 2014 - November 2015 in 10 areas across England, selected from the 150 BL areas to reflect diversity in geographical spread around England and local context. Key 
elements of the latter were population characteristics, urban/rural, contemporary socioeconomic conditions and historical trajectory.

The dataset across the ten field-sites included semi-structured face to face interviews with 116 residents and other stakeholders; a range of participatory activities (e.g. walkabouts guided by residents); and extensive observation of partnership meetings and other events. Informed consent was obtained for all fieldwork. Ethical approval was granted by Lancaster University Research Ethics Committee (03-Feb-2014).

Interview transcripts were anonymised, entered into Nvivo 10 and thematically coded using a common framework for ease of retrieval and cross-referencing during more focussed analysis. In-depth 'within site' and 'cross site' analyses employed a process of analytic memoing (Charmaz 2006; Birks et al., 2008). These assisted the researchers' analysis across the full range of data sources. For the findings reported here the research team identified 'markers' of shifts towards collective control that were commonly triggered during the implementation of BL in participating neighbourhoods. Through cross-site analysis and discussion, the team assigned each marker as occurring within the dimensions of 'Power Within', 'Power With', 'Power To' or 'Power Over'.

Codes linked to the illustrative quotes in the Findings section refer to: fieldwork Areas: A1A10; research method ('Interview' or 'Observation'); participant role ( $\mathrm{R}=$ resident; BLW = Worker employed by the BL Partnership; LP = Local Politician; LGO= Local Government Officer; PM = Big Local Partnership Member; $\mathrm{O}=$ employee of other agencies; LC=Local Councillor).

\section{FINDINGS}

We identified qualitative markers in each of the dimensions of the Collective Control Power Framework, summarised in Box 1 [insert - Box 1: The Emancipatory Power Framework: Empirical qualitative markers in each dimension identified in Big Local fieldwork sites - here].

\section{Markers of 'Power Within'}

Markers of shift toward greater 'Power Within' were mostly but not exclusively identified amongst resident members of BL Partnership. They included evidence of: growing agreement 
over shared values; greater sensitisation to local issues, identifying existing or developing new 'know how' and skills to address these; and increasing sense of group identity and efficacy.

One of the most visible markers in the 'Power Within' dimension was residents coming together and arriving at some sense of 'shared vision' or around priorities for the ongoing collective endeavour by developing and agreeing the neighbourhood plan, a core requirement of the BL initiative. Although these processes were often contested, Partnerships commonly carried out significant consultation with the wider "community" to arrive at some level of negotiated settlement around priorities for the area and how these should be addressed. As one former paid local BL worker explained:

"...we wanted to involve a massive set of groups...we had some training events with about 20 [resident] champions and we said to these people look, you know everything about this area because you're Tenants Association rep, or you're working with young people on the housing estate, or you work...as a volunteer, or you're a local mum we collected probably about 400 ideas ... we had a really high level of engagement...it felt very active...the idea was to look at those ideas, suggest some priorities and some recommendations and then pitch it back to the wider group"(A5-Interview-RLC and previously BLW).

Through development of the neighbourhood plan, BL Partnerships also became more sensitised to local area issues and how to go about addressing them. In some areas the pursuit of areabased knowledge extended to commissioning 'experts' to do research and advise on programmes of work to address specific 'problems', such as poorly utilised green space, a lack of local employment opportunities, fear of crime or social isolation.

Skills development was also a critical sign that residents were developing their capabilities for collective control. While BL frequently attracted residents with a broad range of skills and expertise in such areas as community development, financial administration, research, human resources and fundraising, embarking on BL often required residents to collectively acquire a new set of skills to develop and execute their plans. One local government officer described the extent to which she believed a Partnership was developing the collective skills and ability to effectively implement work locally: 
“...I think it's $[B L]$...provided the skill sets to be able to implement this kind of work locally ... they do challenge...they're challenging themselves constantly and having to consider planning regulations against...like safeguarding issues, getting people into work, contacting local businesses, stop smoking issues, so they've had to get to grips with such a range of issues and that, and they've done really well, and like financial inclusion...I think that they should be proud of themselves to get their heads round some of those difficult things" (A6-InterviewLGO).

Increasing confidence amongst Partnership members in collective ability to effectively address local issues was identified as a further marker of 'power within' - often bolstered by an increase in a sense of shared identify and a growth in their knowledge and skills. This was most evident in views about the importance of maintaining resident ownership over the initiative and clear boundaries around the involvement of external agencies shaping BL activities. As one resident described:

“We don't want to be told what to do by councillors [locally elected politicians], it has got to be resident-led and that's one of the biggest things that we have said as a group" (A3Interview-RPM)

In some cases these views were informed by previous negative experiences of working with or longstanding acrimonious relationships with local councils.

A Partnership's sense of group efficacy was often enhanced through early successes with events organised they organised or unanticipated "wins" over other organisations often considered more powerful. In fieldwork Area 7, for example, observations of Partnership meetings and at community venues revealed that several well-attended community events had generated a sense of pride and achievement as well as expertise and confidence within the Partnership. In another site, following ambivalence prior to a much-anticipated community activity week, a sense of success among partnership members shifted confidence in their ability to achieve their goals in relation to local area change. As one resident member of a Partnership commented: 
"I think what we achieved with Community Week was I think something I said earlier was there were a lot of doubters but we did it. And now we don't have [that] - the doubters are gon." (A9-Interview-RPM).

\section{Markers of 'Power With'}

The most striking marker of the development of 'Power With' was a growing recognition amongst residents involved in BL that organising with other agencies could help them develop a more sustainable programme of neighbourhood improvement. Some emphasised this from the start:

"...for a community to improve and for this money to do what it's meant to be doing, then we need everybody on board...It's the only way we can make the most of it. We are going to need help from the council at times; we are going to need help from the traders and we in return can offer them things as well” (A4 -Interview-PM).

Others were initially ambivalent about forging relationships with external agencies who were viewed negatively for not prioritizing residents' interests in the past, or whose representatives were judged to have previously behaved 'badly'. However, over time in all areas there was growing recognition of the value of Power With:

"You've got to be cautious, and you've got to be accommodating. But you sometimes don't want to be. But you have to work with people... We have had councilors attend meetings... it's generally because they want to suggest where money could be used. And I always feel defensive straightaway. But no, at the back of my heart I do know that yes, work sensibly and use funding properly” (A2-interview-RPM).

A closely related marker of developing Power With was a move from recognising the potential of building alliances, to practical efforts to work together. In some areas existing good relationships meant efforts were quickly rewarded, in others a lot of 'relational work' was needed to reshape previously acrimonious relationships. As a paid worker from one site observed:

“...there's been a lot of feelings of neglect and anger and the local authority knows [it] .... had a bad relationship with people in X [who] feel they've been...promised things and the promises 
are never kept...So there's been a lot of very big contention around all that, which I think is getting a little bit better and I think Big Local has helped"' (A6-Interview-BLW).

\section{Markers of 'Power To'}

Markers of increasing Power To were identified to comprise two elements. The first focused on the emergence of new structures offering opportunities for residents to exercise collective control over decision-making. As already noted the establishment of resident- led Partnerships (initially in some areas referred to as Steering Groups) was a requirement of the initiative and these became the key location for resident-led decision-making. While in a minority of areas the Partnership enveloped a pre-existing (i.e. pre BL), community group, in most areas we observed the establishment of new organisational structures with new membership. Although it was common that many members of these new structures had formerly been involved professionally or voluntarily with community work and/or action locally, they had not previously come together collectively to address local neighbourhood issues. In the main these emergent structures therefore represented new opportunities for already engaged residents to make collective decisions on action to address local issues. Although subject to some ongoing flux, over the study period most of these Partnerships had built up relatively stable membership, regular meeting times and established recognisable physical spaces where decision-making could take place. Other activities such as establishing the internal legal, contractual and financial frameworks necessary to enable Partnerships to manage funds and implement work locally were more complex and required a longer timeline.

In addition to the BL Partnerships, which had the main responsibility for decision-making about priorities and activities, (as highlighted in the discussion of the development of the neighbourhood plan) we also identified the emergence of a range of other formal structures and opportunities for the wider community to contribute to decision making within our study neighbourhoods. These included different forms of consultation surveys, events and wider community or youth forums some of which aimed to increase the accountability of the local Partnership to the wider community.

The findings reported here relate to the first 3 years of BL so markers of the second element of power to - impact of decisions/actions on determinants of social and health inequalities - were understandably limited. However, examples identified during the fieldwork were likely to have been experienced as positive changes by residents. Six Partnerships were establishing 
community hubs (Areas 1, 2, 7, 8, 9 and 10) to increase opportunities for social interaction and involvement of residents in collective activities or to provide advice services. These initiatives could involve existing buildings being transfered to BL Partnerships for renovation (eg Area 2), some with significant symbolic value locally (eg Area 1) or new builds (eg Area 8). Three Partnerships (Areas 1, 8, and 9) were renovating existing, or developing new leisure facilities, including a large multi-use games area (Area 1) and skate park (Area 9) and two were creating new 'pocket' parks/green spaces (Area 3 and 9). One of these (Area3) involved a successful challenge to the local authority's decision to allow all of a piece of land to be used for housing development. One Partnership was also seeking to improve employment opportunities by working with other organisations to provide training for residents (Area 7).

\section{Markers of 'Power Over' operating within communities}

This dimension reflects an understanding of power as dominating and zero sum. It comprises two elements: the exercise of power by a groups of residents over another group in the same neighbourhood or over external 'actors'.

One empirical marker of the exercise by some community members of Power Over others was the development of formal criteria and procedures for selecting new members of BL Partnerships. In some of these instances, Partnerships were apparently legitimating exercising institutional power (Popay et al., 2020) in order to make the running of the Partnership more efficient and transparent as the quote below illustrates:

"If we add to the Executive in the future, it has got to be somebody that is going to contribute; not just somebody who wants to be on... I think the Executive [is], quite fond of having meetings... I wasn't able to see much sign of progress" (A3-interview-RPM).

However, we also observed tensions within Partnerships, which resulted in power being exercised 'illegitimately' by one 'faction' to exclude people they perceived to be 'difficult'. Similarly, resident participation in developing and delivering BL projects often needed 'authorisation' by Partnerships, which on occasions deployed this power over other residents in exclusionary ways.

There were also situations in which BL Partnerships sought to exercise power over the decisions and/or actions of other agencies to protect or advance community interests. In two 
field-sites, for instance, local politicians and their staff were asked to stop attending meetings amid concerns that the Partnership would "become tied to [a] political agenda" (A3-interviewBLW). In another area the Partnership was presented with an invoice for fencing a green area that they had agreed to maintain in exchange for the Local Council ensuring it was safe for public use. The Partnership refused to pay the invoice and the project was shelved because residents believed that the council officers were not keeping to the terms of the agreement.

\section{DISCUSSION}

In this paper - the second of three - we have identified a series of empirical markers of changes in the capabilities disadvantaged communities can acquire during local empowerment initiatives that enable them to exercise collective control over decisions and actions that impact on their lives and health. In our Emancipatory Power Framework (EPF) (described in detail in Part 1 of this series) these capabilities are conceptualised as different forms of power: 'Power Within', 'Power With', 'Power To' (Popay et al., 2020). The EPF also includes the concept of 'Power Over' to allow for the possibility that in some circumstances members of a community may exert collective Power Over an external agency or another group in the same community. This may involve collective action in pursuit of positive change to benefit the whole community (i.e. emancipatory) but could also involve attempts to exercise control over others that is experienced as dominating/oppressive.

Together these four dimensions reflect an extended theory of change for initiatives aiming to increase collective control in disadvantaged communities: from foundation building (Power Within), through alliance making (Power With) to the exercise of collective control in ways that have potential to promote greater social and/or health equity (Power To and the positive use of Power Over) or undermine this (negative use of Power Over).

Markers of 'Power Within' include the acquisition and sharing of knowledge and skills among residents; spoken and visual signs of an increased sense of group efficacy, shared values and interest; and increased expertise and confidence on resident-led Partnerships in their ability to identify and tackle local issues. Recognition of the potential value of working with others and the development of new, or a positive re-shaping of existing relationships with local agencies were identified as markers of the emergence and growth of 'Power With'. 'Power To' was manifest along two axes: the development of processes and structures that enabled residents to participate in decision-making (discussed in more detail in Lewis et al., 2018) and the impact 
of these decisions on improvements in upstream determinants of health and wellbeing. We have also offered markers of both emancipatory and potentially oppressive use of Power Over by residents in BL communities.

These findings make a significant and original contribution to empirical assessment of the collective capabiliteis that emerge and take shape during successful empowerment area-based empowerment initiatives. The markers presented, based on qualitative data, provide practical examples of what capabilities for collective control in each of the power dimensions in the EPF - and changes in these - might 'look like' in practice. Importantly, the empirical markers we have identified are not intended to be exhaustive. Those described here were identified in the first 3 years of a 10+ year programme. If successful, a greater number and variety of markers would be expected to emerge in BL areas over time. The markers could also be supplemented by qualitative research that operationalise some of the other instrumental or organisational outcomes of empowerment processes reported in the current evaluation literature. In line with this, the EPF framework and associated markers are open to ongoing empirical adaption and refinement.

We have argued in this paper that the empirical markers we have identified in 10 neighbourhoods participating in a large-scale English empowerment initiative reveal how these disadvantaged communities are developing the collective power they need to contribute to social transformation and political change for greater equity. We have also identified early instances of these communities exercising this collective control to positively change proximal determinants of inequalities. In our longitudinal evaluation we are continuing to 'test' whether the our Emancipatory Power Framework and associated markers are able to capture the extent to which this power continues to grow and is converted by BL communities to affect significant improvements in the social determinants of health inequalities operating within and beyond the BL neighbourhoods.

In terms of the measurement debates surrounding community empowerment, our approach to identifying markers has strengths and is original in several respects, making a contribution to the sparse literature in this area. First it demonstrates the value and feasibility of using qualitative data to identify, and measure the emergence of, the capabilities required for the exercise of collective control by disadvantaged communities. As has been argued (Laverack and Pratley, 2018; Orton and Ponsford et al., 2019,) such qualitative approaches are an essential 
complement to the overwhelmingly quantitative approaches to measurement that may overlook the intricate, complex relational processes driving empowerment outcomes/impacts. Second, the analysis is located within a framework based on power dynamics, as opposed to the more common instrumental approach, making communities themselves the focus of change. Third it focuses attention on the identification of markers across the empowerment continuum: from the initial stages when power 'within' communities is emerging (ie the internal capabilities communities need to affect greater collective control); through the development of power with as communities recognise the need for, and act to, build alliances; to the exercise of power to deliver improvements in the social determinants of health inequities. Fourth, it recognises that communities may collectively exercise power over others that can be experienced as positive/emancipatory or negative/oppressive.

In Part 3 of this series of papers (Powell et al., 2020) we go on to apply the two power frameworks developed in Part 1, and the empirical markers of emancipatory power described here, to an analysis of the power dynamics operating in participatory spaces associated with the BL programme. The examples of the exercise of Power To in BL neighbourhoods described earlier in this paper - underway by the third year of a ten year programme - are focused inward on improving proximal conditions in neighbourhoods. However, observation of discussions during Partnership meetings suggest that some may shift their gaze outward over time, attempting for example, to influence policy on legal protections for tenants in the private housing sector or eligibility for social protection/welfare benefits. Our on-going evaluation will consider whether this growing 'outward gaze' strengthens over time.

\section{REFERENCES}

Allen, A. (1998) Rethinking Power, Hypatia 13(1), pp. 21-40.

Allen A (2011) Feminist perspectives on power. Stanford Encyclopaedia of Philosophy.

Arendt, H. (1970) On Violence. New York, NY: Harcourt.

Birks, M., Chapman, Y. and Francis, K. (2008). Memoing in qualitative research: Probing data and processes. Journal of Research in Nursing, 13(68), pp. 68-75. 
Charmaz, K. (2006). Constructing grounded theory: A practical guide through qualitative analysis. London: Sage

Cyril, S., Smith, B. and Renzaho, M. (2016) Systematic review of empowerment measures in health promotion. Health Promotion International. 32, pp. 809-826.

Draper, A., Hewitt, G. and Rifkin, S. (2010). Chasing the dragon: Developing indicators for the assessment of community participation in health programmes. Social Science and Medicine, 7, pp.1102-1109.

Laverack, G, (2005). Using a 'domains' approach to build community empowerment, Community Development Journal, 41(1), pp 4-12, https://doi.org/10.1093/cdj/bsi038

Laverack, G. (2006). Improving Health Outcomes through Community Empowerment: A Review of the Literature. Journal of Health Population and Nutrition. 24(1), pp. 113-120.

Lavarack, G. and Pratley, P. (2018). What quantitative and qualitative methods have been developed to measure community empowerment at a national level? WHO Health Evidence Network Synthesis Report 59. Copenhagen: WHO European Region.

Lawson, L. and Kearns, A. (2014). Rethinking the purpose of community empowerment in neighbourhood regeneration: the need for policy clarity. Local Economy, 29, pp.65-81.

Lewis, S, Bambra, C, Barnes, A, Collins, M, Egan, M, Halliday, E, Orton, L, Ponsford, R, Powell, K, Salway, S, Townsend, A, Whitehead, M and Popay, J (2018), 'Reframing "participation" and "inclusion" in public health policy and practice to address health inequalities: Evidence from a major resident-led neighbourhood improvement initiative', Health and Social Care in the Community.

Orton, L. C., Pennington, A., Nayak, S., Sowden, A., Petticrew, M., White, M., and Whitehead, M. (2019). What is the evidence that differences in 'control over destiny' lead to socioeconomic inequalities in health? A theory-led systematic review of high-quality 
longitudinal studies on pathways in the living environment. Journal of Epidemiology and Community Health, 73(10), pp. 929-934.

Orton, L., Ponsford, R., Egan, M., Halliday, E., Whitehead, M. and Popay, J. (2019) Capturing complexity in the evaluation of a major area-based initiative in community empowerment: what can a multi-site, multi team, ethnographic approach offer?, Anthropology \& Medicine, 26(1), pp. 48-64.

Pearce, J. (2013). Power and the twenty-first century activist: From the neighbourhood to the square. Development and Change, 44(3) pp. 639-663.

Popay, J., Whitehead, M., Ponsford, R., Egan, M., and Mead, R., (2020) Power, Control, Communities and Health Inequalities Part I: Theories and Concepts, Health Promotion International.

Powell, K., Barness, A., Bambra, C., De Cuevas, R., Halliday, E., Lewis, S., McGill, R., Orton, L., Ponsford, R., Salway, S., Townsend, A., Whitehead, M. and Popay, J. (2020) Power, Control, Communities and Health Inequalities Part III: Participatory Spaces - an English Case. Health Promotion International.

Reynolds, J., Egan, M., Renedo, A., and Petticrew, M. (2015). Conceptualising the 'community' as a recipient of money - A critical literature review, and implications for health and inequalities. Social Science and Medicine, pp. 143, 88-97.

http://doi.org/10.1016/j.socscimed.2015.08.049

Rissel, C. (1994) Empowerment the holy grail of health promotion? Health Promotion International, 9, pp. 39-47.

Rowlands, J. (1997). Questioning empowerment: working with women in Honduras. Oxford: Oxfam. ISBN 9780855983628

Speer, P. and Peterson, N. (2000). Psychometric properties of an empowerment scale: testing cognitive, emotional and behavioural domains. Social Work Research, 24(2), pp.109-118. 
Starhawk, (1987). Truth or Dare. Encounters with power, authority and mystery. New York: Harper Collins.

Syme, S. L. (1989). Control and health: a personal perspective. In Steptoe, A. and Appels, A. (eds) Stress, Personal Control and Health. John Wiley \& Sons, Oxford, pp. 3-18.

United Nations (2019). High Level Political Forum 2019 under the auspices of ECOSOC. Available at: https://sustainabledevelopment.un.org/hlpf/2019 (Accessed 29 November 2019).

United Nations Economic and Social Council. (2019). Empowering people and ensuring inclusiveness and equality, Report of the Secretary-General, E/2019/65.

Wallerstein, N. (2006). What is the evidence on effectiveness of empowerment to improve health? Copenhagen: WHO Regional Office for Europe (Health Evidence Network Report). Available at: http://www.euro.who.int/ data/assets/pdf file/0010/74656/E88086.pdf ( Accessed 29 November 2019).

Whitehead M., Orton L., Pennington A., Nayak S., Ring A., Petticrew M. et al. (2014) Is Control in the Living Environment Important for Health and Wellbeing, and What are the Implications for Public Health Interventions? Final Report. Public Health Research Consortium. http://phrc.lshtm.ac.uk/papers/PHRC 004_Final_Report.pdf.

World Health Organization. (1986). The Ottawa Charter for Health Promotion. Available at: https://www.who.int/healthpromotion/conferences/previous/ottawa/en/ (Accessed 29 November 2019).

World Health Organization. (1997). Jakarta Declaration on Leading Health Promotion into the 21st Century. Available at: https://www.who.int/healthpromotion/conferences/previous/jakarta/declaration/en/index 1.html (Accessed 29 November 2019). 
World Health Organisation. (2013). Health 2020 policy framework and strategy. Regional Office for Europe Copenhagen: WHO. Available at:

http://www.euro.who.int/ data/assets/pdf file/0020/170093/RC62wd08-Eng.pdf (Accessed 29 November 2016).

World Health Organisation (2019) Driving forward health equity - the role of accountability, policy coherence, social participation and empowerment. Available at:

http://www.euro.who.int/en/publications/abstracts/driving-forward-health-equity-the$\underline{\text { role-of-accountability,-policy-coherence,-social-participation-and-empowerment-2019 }}$ (Accessed 29 November 2019).

Zimmerman M.A. (2000) Empowerment Theory. In: Rappaport J., Seidman E. (eds) Handbook of Community Psychology. Boston, MA, Springer. 
Box 1: The Emancipatory Power Framework: Empirical qualitative markers in each dimension identified in Big Local fieldwork sites

\begin{tabular}{|c|c|c|c|c|}
\hline Defin & $\begin{array}{l}\text { wer within: Capabilities } \\
\text { ternal to a community } \\
\text { pporting/driving collective } \\
\text { ntrol/action }\end{array}$ & $\begin{array}{l}\text { wer with: Capabilities to } \\
\text { ild alliances and act with } \\
\text { hers to achieve common } \\
\text { als. }\end{array}$ & $\begin{array}{l}\text { Power to: Capabilities to } \\
\text { establish spaces for collective } \\
\text { decision-making and } \\
\text { manifestations of exercise of } \\
\text { collective control }\end{array}$ & $\begin{array}{l}\text { Power over other institutions or } \\
\text { exercise of power over a group of } \\
\text { community members by another } \\
\text { group }\end{array}$ \\
\hline $\begin{array}{l}\text { Empirical } \\
\text { markers }\end{array}$ & $\begin{array}{l}\text { *Drawing together existing } \\
\text { skill and expertise across the } \\
\text { community. } \\
\text { *Increasing sense of group } \\
\text { efficacy and confidence in } \\
\text { ability to act together. } \\
\text { *Visible expressions of } \\
\text { 'shared values, interests' and } \\
\text { common identity (e.g. valuing } \\
\text { collective ownership of } \\
\text { decision/actions; agreeing } \\
\text { formal group name, logo, web } \\
\text { presence and recognisable } \\
\text { community hub). } \\
\text { *Developing new collective } \\
\text { knowledge, skill and 'know } \\
\text { how' in relation to addressing } \\
\text { local issues. } \\
\text { *Recognition by activists of } \\
\text { need for breath and depth of }\end{array}$ & $\begin{array}{l}\text { *Recognition of potential } \\
\text { benefits of working with } \\
\text { other institutions or groups } \\
\text { towards common goals. } \\
\text { *Identifying opportunities to } \\
\text { develop relationships and/or } \\
\text { work with others. } \\
\text { *Establishing new or } \\
\text { positively re-shaping } \\
\text { previously acrimonious } \\
\text { relationships with other } \\
\text { institutions. } \\
\text { *Inviting local NGO's, local } \\
\text { government staff, local } \\
\text { politicians and/or local } \\
\text { businesses to participate in } \\
\text { partnership meetings or sit } \\
\text { on advisory boards. }\end{array}$ & $\begin{array}{l}\text { *Formation of new } \\
\text { governance structures with } \\
\text { relatively stable membership, } \\
\text { procedural 'rules', regular } \\
\text { meeting times and } \\
\text { recognisable physical } \\
\text { locations for decision- } \\
\text { making. } \\
\text { *Establishment of } \\
\text { organisational practices; } \\
\text { legal, financial and } \\
\text { governance frameworks. } \\
\text { *An 'opening out' of } \\
\text { opportunities beyond formal } \\
\text { governance spaces for the } \\
\text { wider community to } \\
\text { participate in developing } \\
\text { shared narratives and to } \\
\text { contribute to shared decision- } \\
\text { making on action. }\end{array}$ & $\begin{array}{l}\text { * Arrival and "growth" of BL } \\
\text { changes the balance of power } \\
\text { among decision-making groups in } \\
\text { an area to the benefit of } \\
\text { community 'owned' groups. } \\
\text { *Community activists obtain a } \\
\text { mandate and legitimacy from } \\
\text { extensive consultation with wider } \\
\text { community on local concerns } \\
\text { enables them to exert influence on } \\
\text { local authority priorities. } \\
\text { *Local politicians and their staff } \\
\text { refused access to BL meetings } \\
\text { until members are sufficiently } \\
\text { confident of their ability to retain } \\
\text { control over decision-making } \\
\text { processes. } \\
\text { *Lack of transparency in use of } \\
\text { rules and procedures by some } \\
\text { Partnership members to }\end{array}$ \\
\hline
\end{tabular}




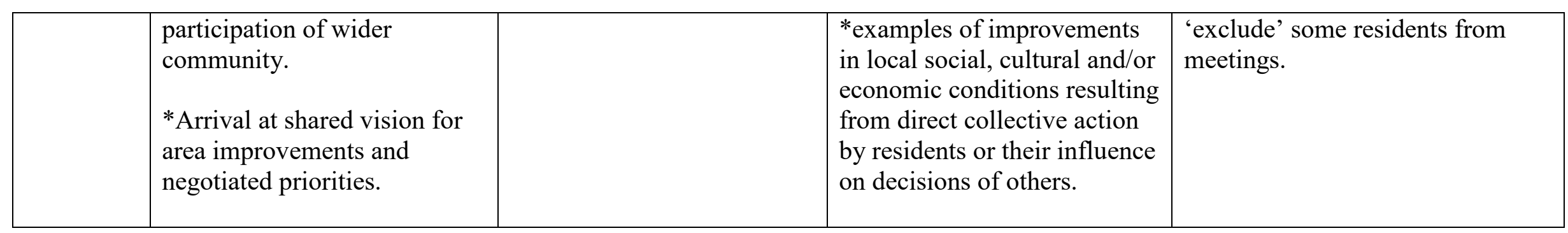

